\title{
BMJ Open Development and pilot implementation of a standardised trauma documentation form to inform a national trauma registry in a low-resource setting: lessons from Tanzania
}

\author{
Hendry R Sawe (D) , ${ }^{1}$ Teri A Reynolds, ${ }^{2}$ Ellen J Weber, ${ }^{3}$ Juma A Mfinanga, ${ }^{4}$ \\ Timothy J Coats, ${ }^{5}$ Lee A Wallis (i) ${ }^{6}$
}

To cite: Sawe HR, Reynolds TA, Weber EJ, et al. Development and pilot implementation of a standardised trauma documentation form to inform a national trauma registry in a low-resource setting: lessons from Tanzania. BMJ Open 2020;10:e038022. doi:10.1136/ bmjopen-2020-038022

- Prepublication history for this paper is available online. To view these files, please visit the journal online (http://dx.doi org/10.1136/bmjopen-2020038022).

Received 26 February 2020

Revised 16 August 2020

Accepted 01 September 2020

Check for updates

(C) Author(s) (or their employer(s)) 2020. Re-use permitted under CC BY-NC. No commercial re-use. See rights and permissions. Published by BMJ.

For numbered affiliations see end of article.

Correspondence to

Dr Hendry R Sawe;

hendry_sawe@yahoo.com

\section{ABSTRACT}

Objectives Trauma registries are an integral part of a well-organised trauma system. Tanzania, like many low and middle-income countries, does not have a trauma registry. We describe the development, structure, implementation and impact of a context appropriate standardised trauma form based on the adaptation of the WHO Data Set for Injury (DSI), for clinical documentation and use in a national trauma registry.

Setting Our study was conducted in emergency units of five regional referral hospitals in Tanzania.

Procedures Mixed methods participatory action research was employed. After an assessment of baseline trauma documentation, we conducted semi-structured interviews with a purposefully selected sample of 33 healthcare providers from all participating hospitals to understand, develop, pilot and implement a standardised trauma form. We compared the number and types of variables captured before and after the form was implemented.

Outcomes Change in proportion of variables of DSI captured after implementation of a standardised trauma documentation form.

Results Piloting and feedback informed the development of a context appropriate standardised trauma documentation paper form with carbonless copy that could be used as both the clinical chart and data capture. Among 721 patients (seen by 21 clinicians) during the initial 30 -day pilot, overall variable capture was $86.4 \%$ of required variables. After modifications of the form and training of healthcare providers, the form was implemented for 7 months, during which the capture improved to $96.3 \%$ among 6302 patients (seen by 31 clinicians). The providers reported the form was user-friendly, resulted in less time documenting, and served as a guide to managing trauma patients.

Conclusions The development and implementation of a contextually appropriate, standardised trauma form were successful, yielding increased capture rates of injury variables. This system will facilitate expansion of the trauma registry across the country and inform similar initiatives in Sub-Saharan Africa.
Strengths and limitations of this study

- This participatory action research generated a model form for capturing all variables required for the WHO Data Set for Injury that may be used and adapted in other low-resource settings working to develop trauma registries.

- The development of a structured, paper-based data form that could also be used as the chart demonstrated a feasible and sustainable method for providing data for a registry, while also improving the quality of injury care and documentation, provides a model for developing a trauma registry in other limited resource countries.

- This study was conducted at a selected sample of regional level hospitals, which limits the generalisability to the whole healthcare system, as regional level hospitals tend more have human and infrastructural resources than lower level facilities.

- There is a possibility that providers demonstrated a substantial improvement in capture of injury variable due to their awareness of being observed; however, capture remained significantly higher even at 7 months a point at which we would expect that the 'Hawthorne effect' would no longer be at play. Subsequent follow-up is planned.

\section{BACKGROUND}

Trauma is responsible for approximately 5.8 million deaths annually, accounting for $10 \%$ of all deaths worldwide. ${ }^{1}$ Ninety per cent of these deaths occur in low/middleincome countries (LMICs). ${ }^{2}$ Evidence from high-income countries suggests that improving trauma care systems could substantially reduce trauma-related morbidity and mortality in LMICs. Trauma care systems in most LMICs are underdeveloped and, in places where they exist, high volume of trauma leaves systems under-resourced and overburdened. $^{3}$ 
Trauma registries are critical to both prevention of traumatic injuries, and the development and improvement of trauma care. ${ }^{4}$ Trauma registries are databases that contain prospectively collected information on trauma patients, including demographics, injury mechanisms and severity, treatment and disposition. Registries allow the healthcare system to assess the quality of trauma care, apportion resources, monitor the impact of performance improvement on quality of care and public health interventions to prevent injuries. ${ }^{5-7}$

Trauma registries form an integral component of the trauma care system in most high-income countries. However, trauma registries in LMICs are largely nonexistent. ${ }^{8}$ In the few hospitals where registries exist, they are developed in short-term research projects that are not sustainable, ${ }^{910}$ and they are not linked at a national level, preventing evaluation of the system as a whole. ${ }^{11} 12$ Tanzania does not have a national trauma registry. The first Tanzanian effort to develop a trauma registry was at the Muhimbili National Hospital (MNH) in Dar es Salaam, and it has been very successful for capturing trauma data seen at this referral hospital ${ }^{13}$; however, thus far these efforts have been limited to MNH. These experiences have since informed the development of WHO clinical form. ${ }^{14}$ The Ministry of Health $(\mathrm{MoH})$ uses a purpose-designed Health Management Information System (HMIS) register, which gathers information on all patients visiting health facilities throughout Tanzania. ${ }^{15}$ HMIS documentation is performed by the treating clinicians, in addition to their clinical charts, and then data aggregation is performed by a clerk at each facility and submitted to MoH. HMIS data entry creates an additional burden in time and costs for the physician and hospital, which affects the quality and volume of data reported. ${ }^{16} 17$

To provide guidance on the establishment of trauma registries in LMIC's, the WHO proposed the Data Set for Injury (DSI) ${ }^{18}$ a minimum set of variables needed for a centralised trauma registry as well as a standardised clinical form for trauma patients. ${ }^{14}$ However, when we studied the capture of these variables in routine clinical documentation, we found a poor capture of variables documented. In a mixed-methods study of documentation for trauma patients in five regional hospitals in Tanzania, we found poor availability of requisite data and a very low capture $(33.6 \%)$ of DSI variables using existing documentation methods, as well as potential barriers and facilitators to complete documentation. ${ }^{19}{ }^{20}$ Results of these studies were, paradoxically, encouraging as they suggested vast potential and a way forward for improving trauma data capture.

To facilitate implementation of a sustainable trauma registry in Tanzania, a contextually appropriate mechanism of collecting relevant data is needed. This study describes the development, piloting and implementation of a low-burden system based on an adaptation and utilisation of the WHO DSI as the first step in the development of a national trauma registry in our country. The primary aims of the project were to ensure all eligible trauma patients are included and maximising the capture of variables within the standardised trauma form.

\section{METHODS}

A participatory action research study was conducted between 1 February 2018 and 30 September 2019 at five regional referral hospitals in Tanzania (Morogoro, Arusha, Mwananyamala, Coastal and Tanga). ${ }^{19}$

The process of development and implementation of a system to collect standardised trauma variables was guided by Susman and Evereds' cyclic process of inquiry for action research ${ }^{21}$ (figure 1). The first two phases of this process ('diagnosis' and 'action planning') were previously undertaken during the aforementioned needs assessment studies, ${ }^{19} 2022$ and are briefly described here.

\section{Diagnosis}

First, we conducted a prospective, observational crosssectional study to evaluate capture of the variables in the WHO DSI among all trauma patients presenting to the Emergency Units (EUs). This revealed poor capture $(33.6 \%)$ of the recommended variables. ${ }^{19}$ Following this analysis, we conducted a qualitative study using focus groups at these five hospitals to understand the barriers and facilitators for capturing required data. ${ }^{20}$ Among the barriers were provider knowledge, and the burden of dual documentation.

\section{Action planning}

During these discussions, the investigators and participants determined that a solution to the barriers identified in diagnosis phase would be a standardised trauma data collection tool that could also be used as a chart, and created a plan to develop and pilot test it. The development of the tool was further informed by semistructured interviews with providers at the EU's, aimed at understanding their perception and attitudes towards using a standardised chart with prespecified variables for providers to complete for all trauma patients. ${ }^{22}$

\section{Action taking}

The 'diagnosis and action planning' phases led to the design of context-appropriate standardised trauma documentation form based on the adaptation of the WHO DSI and clinical form. ${ }^{14}$ Usability of the form was evaluated by healthcare providers at all EUs, after which semi-structured interviews were again conducted to assess perceptions and attitudes of healthcare providers regarding utilisation of the form, and soliciting input on the design and variables within the form and how it could be implemented without dual documentation. This feedback was reviewed and incorporated into a final draft of the form. ${ }^{22}$

The current report summarises further steps in 'action taking' followed by 'evaluation' and 'specifying learning', the final two stages of the cyclic process of inquiry for action research. 


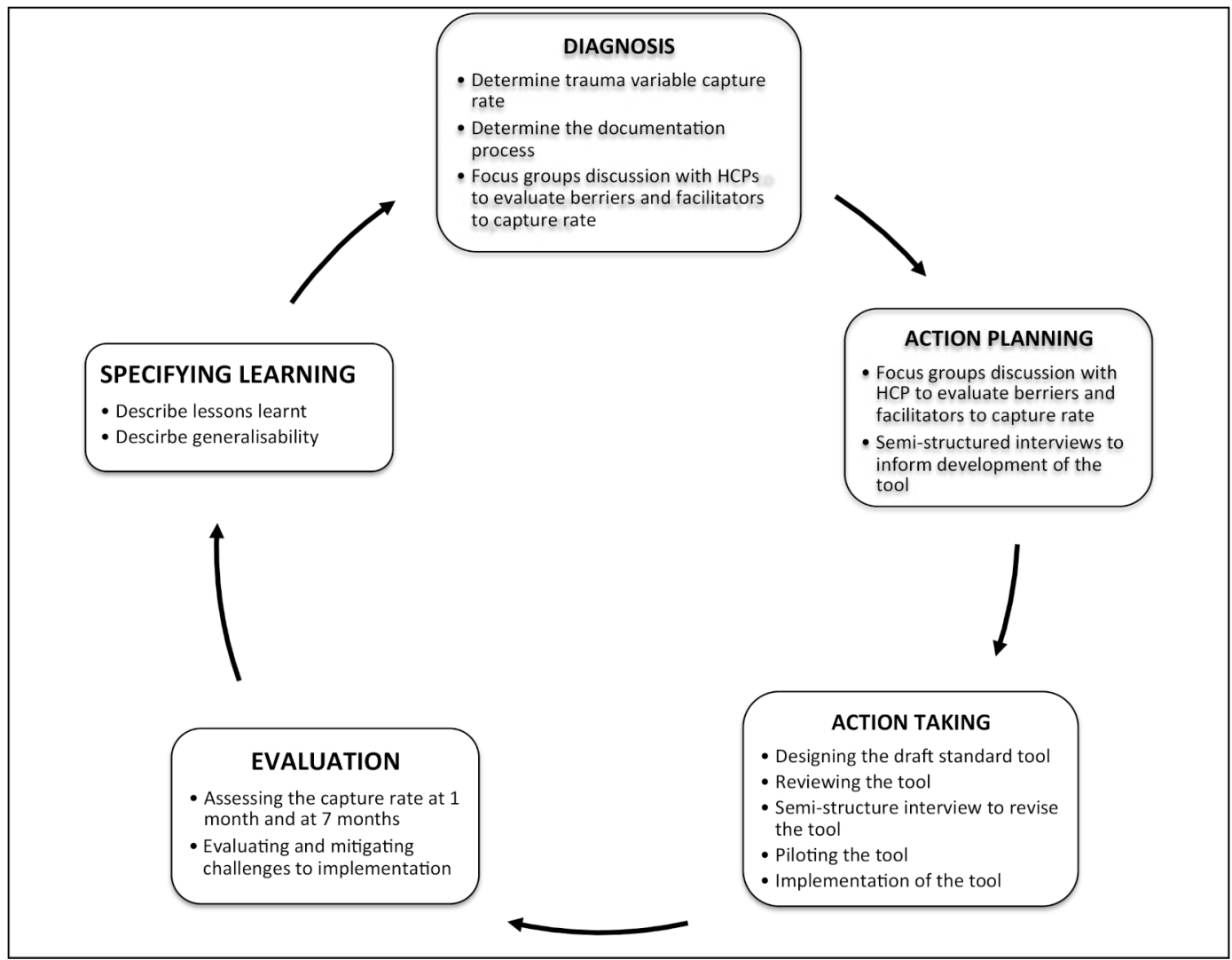

Figure 1 Five steps of participatory action research for development and implementation of the standardised trauma documentation form, based on Susman and Evereds' cyclic process of inquiry for action research. HCPs, Heathcare providers.

\section{Training of HCPS}

Two clinical care leads (a nurse and a physician) from each EU were invited to participate in a 2-day training of trainer (ToT) course, conducted at MNH. The ToT course focused on basic components of the primary trauma care, ${ }^{23}$ importance and definition of each DSI variable, associated documentation in the standardised trauma form including practice on filling out the form using different scenarios of preprepared hypothetical trauma cases, and how the variables will link with registry. After the ToT, the clinical leads conducted one-on-one training of clinicians in their respective EUs who are involved in the care of trauma patients. The one-on-one training invoved filling out the proposed standardised clinical documentation form on a sample of patients who presented at EU during clinical shift. The ToT reviewed the clinical charts and provided feedback in real time to clinicians on different aspects of completing the form, including explaining any variables or components that were not clear to the clinicians. The trained clinical leads were also used as the key personnel (superusers) supporting day-to-day queries on use of the standardised trauma form at their respective EUs.

Pilot testing and modification of the form

After providers had been trained at all EU's, we conducted a 1-month pilot in January 2019. The form was printed with a carbonless copy, and clinicians were expected to document their clinical care and trauma variables on the form. Then, the top copy could be removed to become part of the patient's chart, while the bottom copy was retained to inform the registry. In each $\mathrm{EU}$, research assistants-clinical officers (middle level providers with diploma in clinical medicine) and nurses received extensive training on how to capture data electronically, and prior to this phase of the study, they all had participated in data collection for the baseline observational study, ${ }^{19}$ reported in the diagnostic phase.

The research assistant collected the bottom copy of the clinical form and entered the data to an online Research Electronic Data Capture (REDCap) software (REDCap, San Francisco, California, USA). For each variable, the research assistant entered the documentation of the physician and the REDCap version of the form had options to indicate for each variable whether it was documented, and whether there was an error in the documentation. Errors were defined as documenting data that didn't match the variable requested. Data from REDCap were exported to Statistical Package for Social Science (SPSS) (V.22.0, IBM) and analysed.

The number of patients for whom forms were completed was compared with the main hospital register, and the capture of each variable was calculated as the number of variables documented divided by the total of variables for each patient. The proportion of errors was calculated as number of documented variables with errors divided by the number of documented variables. 
The principle investigator (a specialist emergency physician, HRS) provided feedback to the providers in the EUs on the results. HRS then conducted consultative interviews with trauma care providers in each $\mathrm{EU}$ to obtain feedback on the understandability and usability of the form, and challenges to its completion. Interview participants at each EU were purposefully selected based on their involvement in the trauma care process and to maximise the variation in cadres and work experience of the interviewees. The challenges identified in the interviews were then addressed by modification of the form and online REDCap variables, additional one-on-one informal training, feedback to individual providers on their documentation, and enlisting the hospital administration to advocate during clinical meetings for accurate use of the form for clinical documentation of all trauma patients.

\section{Implementation of the standardised trauma documentation form}

The refined standardised trauma documentation form (clinical chart) was launched for a 7-month period from end of February 2019 to September 2019. We conducted a preplanned interim analysis of data 30 days into the implementation to ensure the revised form was working well, with improved capture of variables and fewer errors. As in the pilot, all trauma patients who presented to the EU and seen by clinicians were supposed to have documentation completed using the standardised trauma form. Process for data collection and analysis was the same as after the pilot, with one copy of the form becoming part of patient's medical chart, and the other used for data entry in the trauma registry by the research assistant. The research assistants entered the data into REDCAP both with regard to whether the data was present and whether there was an error in the documentation.

\section{Evaluation}

During the 7-month implementation period, the principal investigator (PI) reviewed a random sample of the paper form and the entry of data and notation of errors into the REDCap by the research assistant. If the research assistant marked something as an error that wasn't, or failed to spot an error, the PI corrected the entry in RedCAP. The PI provided feedback to clinical leads of each site and the research assistants on the observed variable capture as well as supporting to troubeshoot any challenges that are related to data collection and entry. After quality check, data from REDCap system were exported to SPSS and analysed. The capture of each variable was calculated as the total number of variables documented or documented as not done (ND) or documented as unknown divided by the total of variables for each patient. Then, the proportion of documented DSI variables during the study period was compared with the proportion captured during the initial needs assessment (when the standardised form did not exist and only existing records were evaluated). ${ }^{19}$ DSI variables were aggregated into five main categories to demonstrate the change in the proportion of variables completed from baseline to 7-months post implementation.

\section{Specifying learning}

The authors reflect on key lessons on engagement, development and implementation of standardised trauma documentation form in the discussion.

\section{Patient and public involvement}

The development of standardised form to inform a national trauma registry is in response to the public health need of preventing injury and improving care of the injured by acquiring better evidence. Patients and the public were not involved in the design of the study. The results of our study will be disseminated through open access publications.

\section{RESULTS}

\section{Action taking}

Pilot testing and modification of the standardised trauma documentation form

During the pilot in January 2019, 21 clinicians across the five EUs of the regional hospitals saw 721 trauma patients. The proportion of variables completed, and errors showed marked variation by variable. Patient name was documented $100 \%$, whereas others were poorly documented (table 1). Documentation of mental status (Glasgow Coma Scale (GCS) or Alert Verbal Painful Unresponsiveness (AVPU) scale was $61.3 \%$ complete with $30.5 \%$ errors among those entries; a key DSI variable 'mechanism of injury' was missing in $28 \%$ of cases with $12.3 \%$ having errors (table 2). There was also evidence of bias in the data that was missing, as most of the $11.5 \%$ of patients who did not have a disposition recorded were in fact discharged.

Thirty-three healthcare providers who had previously been interviewed for the design of the form were again interviewed after the first pilot (table 3); their demographics are discussed elsewhere. ${ }^{22}$ These interviews revealed the need to collect additional information critical for the Tanzanian context, and necessary for clinical care, including medicolegal data points. Suggested changes included:

- Expansion of the demographics section to ensure that the mode of arrival captures traditional means of travel in Tanzania.

- Designated spaces for documenting: chief complaints; results; reassessment of patients, including vital signs prior to patients exiting EU; and mass casualty incident occurrences.

- Additional check boxes to indicate mass casualty incidents, normal assessment for all primary and secondary survey, and for the most common investigations.

- Removal of the pain scale assessment (as this is not in their routine clinical care and they are not conversant with the scale).

- Adjustment of font to at least 12 point. 
Table 1 Capture of DSI variables before, during pilot and after 7-month implementation phase of standardised trauma documentation form

\begin{tabular}{|c|c|c|c|c|}
\hline \multirow[b]{3}{*}{ Variable } & \multicolumn{4}{|c|}{ Injury variable capture } \\
\hline & $\begin{array}{l}\text { Pre implementation } \\
(\mathrm{N}=2891)\end{array}$ & Pilot $(\mathrm{N}=721)$ & $\begin{array}{l}\text { Post implementation* } \\
(\mathrm{N}=6302)\end{array}$ & $\begin{array}{l}\text { ND or unknown } \uparrow \\
(\mathrm{N}=6302)\end{array}$ \\
\hline & $\%$ & $\%$ & $\%$ & $\%$ \\
\hline \multicolumn{5}{|l|}{ Patient demographics } \\
\hline Name of the patient & 99.3 & 100 & 100 & 4.3 \\
\hline Age or date of birth & 82.0 & 84.9 & 97.3 & 3.8 \\
\hline Gender & 69.7 & 84.2 & 99.3 & 0 \\
\hline Address of the patient & 83.8 & 89.9 & 95.4 & 5.4 \\
\hline Injury geographical location & 14.1 & 95.6 & 94.5 & 3.3 \\
\hline \multicolumn{5}{|l|}{ Initial clinical condition } \\
\hline Referral status & 8.3 & 85.6 & 94.1 & 3.7 \\
\hline Date of EU care & 80.9 & 91.4 & 99.8 & 0 \\
\hline EU arrival mode & 23.6 & 83.9 & 99.7 & 5.9 \\
\hline Signs of life & 31.2 & 89.2 & 94.8 & 0 \\
\hline Time of first vital signs & 32.2 & 96.3 & 95.6 & 6.5 \\
\hline Initial heart rate & 24.5 & 93.5 & 95.8 & 9.6 \\
\hline Initial SBP & 18.7 & 90.3 & 97.1 & 15.2 \\
\hline Respiratory rate & 18.0 & 88.2 & 99.7 & 11.1 \\
\hline Saturation of oxygen & 13.1 & 84.2 & 98.5 & 18.5 \\
\hline Initial GCS/AVPU & 3.1 & 61.3 & 92.1 & 2.0 \\
\hline First provider assessment time & 32.2 & 91.4 & 94.1 & 0 \\
\hline \multicolumn{5}{|l|}{ Details of injury } \\
\hline Mechanism of injury & 45.0 & 72.0 & 95.5 & 1.3 \\
\hline Mass casualty event & 0.5 & 82.2 & 94.5 & 0.2 \\
\hline Injury event date & 52.2 & 74.5 & 96.3 & 0 \\
\hline Injury settings & 5.3 & 84.6 & 98.9 & 8.0 \\
\hline Activity at time of injury & 3.3 & 87.2 & 100 & 8.9 \\
\hline Injury intent & 6.8 & 84.5 & 91.1 & 2.1 \\
\hline Protective devices & 32.0 & 80.0 & 97.3 & 7.6 \\
\hline \multicolumn{5}{|l|}{ Injury examination } \\
\hline Type of injury & 72.1 & 87.4 & 92.6 & 0 \\
\hline Injury anatomical location & 9.2 & 79.9 & 92.1 & 0 \\
\hline Defined serious injuries & 1.3 & 90.3 & 99.1 & 2.2 \\
\hline \multicolumn{5}{|l|}{ Emergency unit details } \\
\hline Interventions done at EU & 33.0 & 90.4 & 92.7 & 4.9 \\
\hline Time of EU departure & 15.3 & 93.3 & 95.2 & 2.1 \\
\hline EU disposition & 62.9 & 88.5 & 100 & 1.1 \\
\hline
\end{tabular}

*Field was filled with data or not done (ND) or unknown.

†Variables documented as ND or unknown.

DSI, Data Set for Injury; EU, Emergency Unit.

Using this provider input, we updated the form (online supplemental file 1 ).

In addition to improvements in the form, the interviews revealed that some EU providers needed greater clarity on some of trauma variables, as well as means of distinguishing lack of documentation (missing data) from something that could not be done due to lack of resources, process or expertise to perform the intervention. An adjustment was made 
Table 2 Documentation error in variables during pilot and implementation of the standardised trauma documentation form

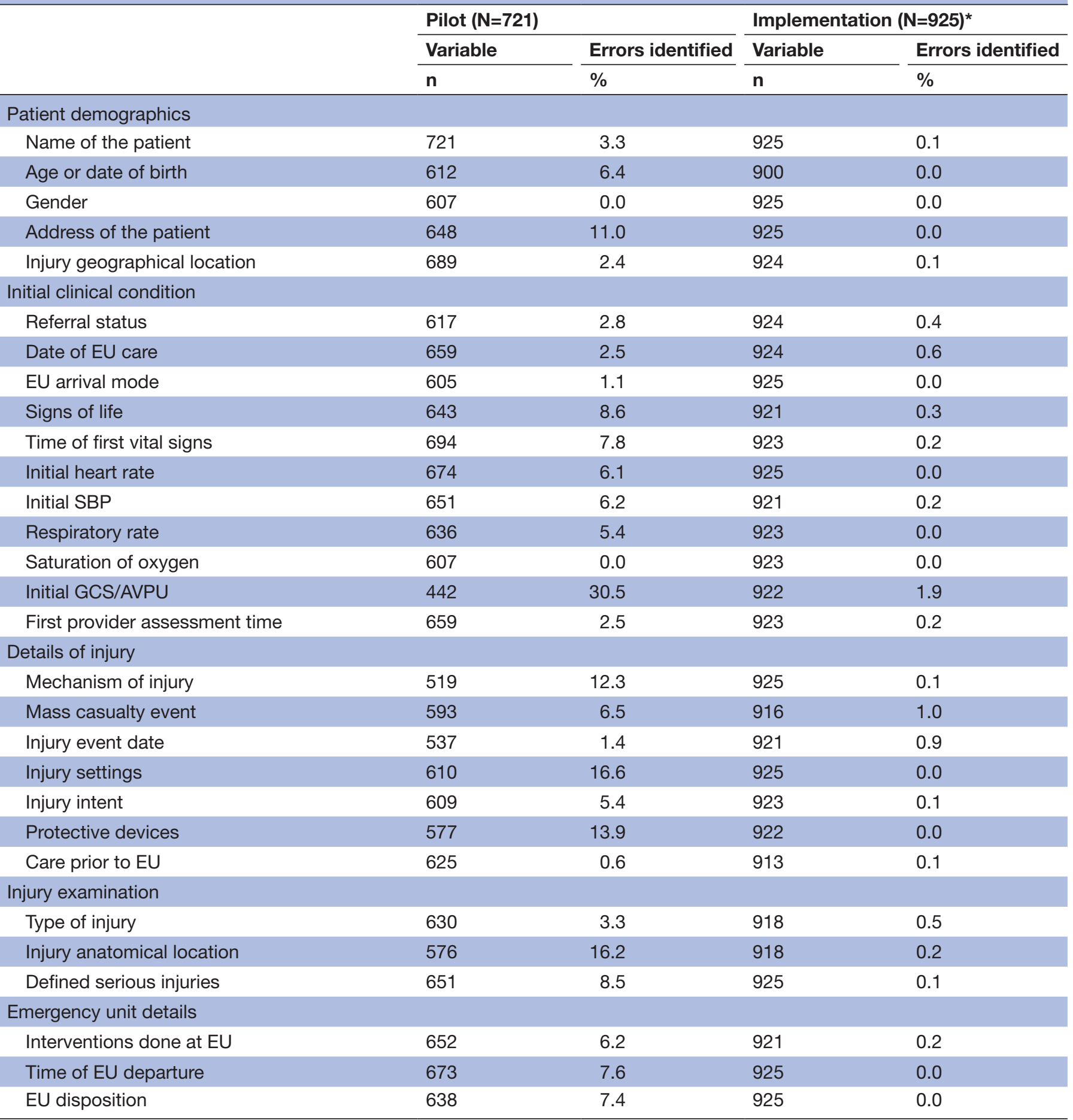

${ }^{*}$ During the first 30 days post implementation.

EU, Emergency Unit; GCS, Glasgow Coma Scale; SBP, Systolic Blood Pressure.

to allow the providers to document ND or unknown in all variables that were not done (ND) in the EU or information is unavailable from patient so as to distinguish the lack of documentation (missing data) from something that can not be done due to lack of resources, process or expertise to perform the intervention (eg, a blood pressure was recorded ND if there was no equipment to make the measurement), and all were analysed as documented. All EUs went on to conduct additional one-no-one internal training to clinicians by clinical care leads, as well as daily advocacy to improve understanding of the form's relevance to clinical care and data.

\section{Evaluation}

The final form was implemented from end of February 2019. The preplanned interim analysis 30 days after 
Table 3 Demographics of healthcare workers in semistructured interviews

\begin{tabular}{ll}
\hline Hospital role & $\begin{array}{l}\text { Interviewed } \\
\text { (n, \%) }\end{array}$ \\
\hline Nurse & $6(18)$ \\
\hline Medical officer & $8(24)$ \\
\hline Assistant medical officer & $5(15)$ \\
\hline Clinical officer & $6(18)$ \\
\hline Specialist physicians & \\
\hline \multicolumn{1}{|c}{ Emergency specialist physician } & $1(3)$ \\
\hline Orthopaedic/trauma specialist physician & $1(3)$ \\
\hline \multicolumn{1}{c}{ Surgery specialist physician } & $1(3)$ \\
Administrator & $2(6)$ \\
\hline HMIS officer & $2(6)$ \\
Information and communications & $1(3)$ \\
technology officer & \\
\hline
\end{tabular}

HMIS, Health Management Information System.

implementation included 925 patients seen by 23 clinicians, and found overall data completion and errors improved substantially across all categories (figure 2). The overall documentation increased from baseline in the diagnostic phase $(33.6 \%)$ in July $2018^{19}$ to $96.3 \%$ at 7-month post implementation, a substantial improvement from 33.6\% observed during the 'diagnostic' phase, and improvement was across all categories (table 1). Details of injury (from $20.7 \%$ to $96.2 \%$ ), initial clinical condition (from $26 \%$ to $96.5 \%$ ) and injury examination (from $27.5 \%$ to $94.6 \%$ ) had the largest improvements in documentation (table 1). Age, activity at time of injury and disposition plan were documented in all patients post implementation. Some variables remained below $100 \%$ capture, including injury intent $(8.9 \%$ missing $)$, injury anatomical location ( $7.9 \%$ missing), injury type $(7.4 \%$ missing) and interventions in EU ( $7.3 \%$ missing).

The use of the option for ND or unknown highlighted several gaps in the ability or processes of these departments to manage trauma patients. These variables included the setting of the injury and activity at the time, and vital sign data which were marked ND in $9.6 \%-18.5 \%$ of cases (table 1). However, the use of ND did not fully account for the improvement in documentation.

\section{DISCUSSION}

Countries that have no trauma registries are limited in their capacity to correctly define the burden of injury, reduce injury rates and develop contextually-appropriate strategies to improve care processes. ${ }^{10}$ This participatory action research generated a model form for capturing DSI variables that may be replicable in other low-resource settings working to develop trauma registries. Inclusion of DSI variables will allow for comparison with other countries.

High-quality documentation of trauma cases can serve several crucial purposes both at national and hospital levels. ${ }^{24}$ Trauma registries have provided the ability to better understand sources of injury and patient outcomes, and to make interhospital or regional comparisons that potentially indicate best practices. Trauma registry data in high-income countries have demonstrated impact of trauma care reorganisation on overall patient mortality over a period of 10 years, and more recently enabled recognition of a demographic shift of age and injury mechanisms among trauma victims. ${ }^{25} 26$ Such detailed information is desperately needed in most LMICs, given

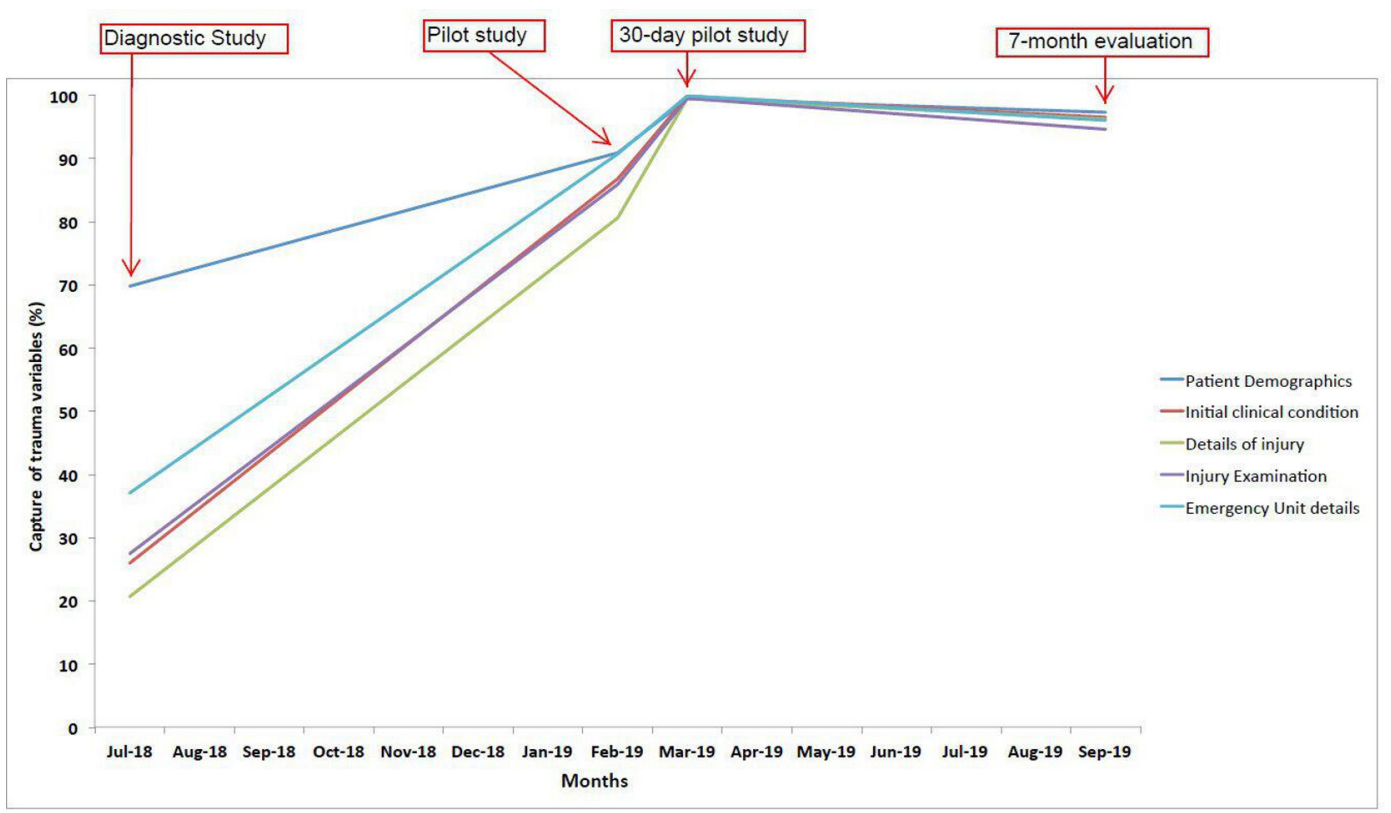

Figure 2 Capture of trauma variable categories over 7-month implementation phase of standardised trauma documentation form. 
the need to apportion our limited resources to maximise patient outcomes.

However, guaranteeing sustainable quality data from facilities requires an understanding by all staff and institutional management as to why documentation can impact outcomes $^{27}$ as well as to provide a feasible way to do it. It is likely that numerous factors led to the successful implementation of the form at different EUs. Its development relied on substantial groundwork, including a needs assessment to evaluate baseline capture of DSI variables, and evaluation of facilitators and barriers to implementation as well as education as to the value of the data. The engagement of healthcare providers and administrators at all stages in diagnosis, development and implementation yielded valuable input to modify the tool and promoted wide acceptance. Iterative pilot testing was crucial for refinement, as was feedback interviews. Furthermore, this feedback identified additional reasons for lack of documentation that could be addressed by additional training of providers on primary trauma care. ${ }^{28}$ As one of the first locally developed trauma forms to incorporate WHO DSI variables, the final tool we developed can now been used to inform the implementation of WHO International Registry for Trauma and Emergency Care ${ }^{29}$ using data from Tanzania.

Inevitably, we encountered several challenges. The form's development involved introduction of WHO DSI variables, most of which were not routinely documented by the providers. Robust training was necessary to not only teach HCPs how to use the form, but also reinforce its value and alter negative perceptions surrounding its implementation. Changing clinicians' mindsets required strong support from administration, and a willingness to use its authority and supervision to ensure compliance. Because providers frequently rotate in and out of departments, sustainability of the process was aided by the train of trainers programme, so that each EU could perform its own training as needed. The variability in providers' training and experience meant training had to be tailored to non-emergency physicians, to ensure all providers understood variables and documented them correctly. Similar to previous observations, ${ }^{30} 31$ we found most EUs had limited equipment and consumables to support the provision of high-quality emergency care. This was identified as one of the reasons why some variables were poorly captured. In our training, and formatting of the standardised form, we added a component to indicate that a particular assessment, investigation or intervention was $\mathrm{ND}$, or is unknown to help distinguish lack of documentation from inability to perform the evaluation. It was notable that the variables most likely to have an ND were those of assessment of vital signs, which is a fundamental need in all trauma cases. This suggests a gap, that requires additional training and resources to appropriately care for patients. The use of unknown for name, age and address of patient may suggest the inability patient to respond due to either being altered or brought in with fatal injuries, as trauma patients in our settings may be brought to EU by good Samaritan, or police from the scene of injury. ${ }^{32}$ Similarly for activity being performed at the time of the injury, and setting, may suggest either a failure to ask the question or the inability of the patient to respond.

A key to the sustainability of the form, and support from providers is that it does not contribute to existing strains in their roles. ${ }^{561133}$ Prior to the development of the tool, providers had to endure dual documentation to report each case in the HMIS register. ${ }^{15}$ Reducing the amount of documentation at facility level has been shown in similar settings to improve compliance, data capture and reduce provider fatigue. ${ }^{34}$ Most registries use dual documentation systems, which require an additional clerk around the clock to ensure complete capture, ${ }^{11} 35$ which would not be feasible in our setting. In high-income countries, prior to electronic charts, carbonless copies were frequently used in emergency departments to support clinical documentation and billing. In our setting, they support and improve capture of injury variables in LMICs without dual documentation. If electronic records are eventually adopted throughout Tanzania, the data could be directly imported into a trauma registry while also serving as a clinical record.

Nevertheless, long term consistency of data collection is a challenge in most settings. ${ }^{10}$ In this study, 7 months after implementation of the form, capture was still very high, though there was a slight decline from the interim analysis at 30 days post implementation. Several factors might have contributed to this decline, including knowledge retention issues, staff turnaround and changes in-patient flow through EUs. Additional research is necessary to identify best practices for mitigating these issues.

\section{Limitations}

Our study had several limitations. We conducted the study at selected sample of regional hospitals in Tanzania, which may not represent the whole healthcare system of the country, as regional hospitals tend to have more resources and preferentially qualified providers than lower facilities. There was only one assessor for each chart at each site, and thus inter-rater reliability of the data input and assessment of errors by research assistants could not be assessed; the PI reviewed a selected sample of charts and made only few correction to the online data; however, inter-rater reliability was not assessed. Future initiatives will focus on assessing the quality of variable captured, as well as consistency at each site so as to ensure high-quality data for trauma reporting. Our capture post pilot was determined using all documentation (including the use of ND and unknown for variables documented as ND due to lack of resources, process or expertise) which limit generalisability to settings with more resources for care that may require more documentation of performed assessment or interventions. Furthermore, there is a possibility that providers in the EU demonstrated a significant improvement in documentation due to their awareness of being observed ${ }^{36}$; however, capture remained significantly 
higher than baseline even at 7 months, a point at which we would expect that the 'Hawthorne effect' would no longer be at play. Subsequent follow-up is planned.

\section{Conclusion}

Through participatory action research, a contextually appropriate, standardised trauma documentation form was successfully developed and implemented, yielding marked improvement in the capture of essential injury variables. This system will facilitate expansion of the trauma registry across the country and inform similar initiatives in other countries in Sub-Saharan Africa. Future work should focus on expanding the existing registry to broader network of hospitals, utilisation of the existing dataset to inform on the burden of injury in the region and addressing challenges associated with longterm consistency of the registry.

\section{Author affiliations}

${ }^{1}$ Emegency Medicine, Muhimbili University of Health and Allied Sciences, Dar es Salaam, United Republic of Tanzania

${ }^{2}$ Integrated Health Services, World Health Organization, Geneva, Switzerland ${ }^{3}$ Emergency Medicine, University of California San Francisco, San Francisco, California, USA

${ }^{4}$ Emergency Medicine, Muhimbili National Hospital, Dar es salaam, United Republic of Tanzania

${ }^{5}$ Cardiovascular Sciences, University of Leicester, Leicester, UK

${ }^{6}$ Emergency Medicine, University of Cape Town, Cape Town, South Africa

Acknowledgements The authors thank Ministry of Health, Community Development, Gender, Elderly and Children, and management and staff at participating hospitals. We extend special thanks to the Heads of participating EUs: Nanyori Lukumay (Arusha), Nafsa Marombwa (Morogoro), Raymond Makona (Mwananyamala), Siaely Moshi (Coastal), and Aris Banda (Tanga).

Contributors HRS contributed to the conception and design of the study, acquired, analysed and interpreted the data, and drafted original manuscript and revised the manuscript. TR contributed to the design of the study, assisted with data interpretation, and read, revised and approved of the final manuscript. EW contributed to the design of the study, assisted with data interpretation, and read, revised and approved of the final manuscript. JAM contributed to the design of the study, data validation, and analysis and read, revised, and approved of the final manuscript. TC contributed to the design of the study, assisted with data interpretation, and read, revised and approved of the final manuscript. LAW contributed to the design of the study, assisted with data interpretation, and read, revised and approved of the final manuscript.

Funding The authors have not declared a specific grant for this research from any funding agency in the public, commercial or not-for-profit sectors.

Competing interests None declared.

Patient consent for publication Not required.

Ethics approval The study protocol was reviewed and approved by the Institutional Review Board of the Muhimbili University of Health and Allied Sciences (MUHAS) and The Ministry of Health, Community Development, Gender, Elderly and Children of Tanzania issued a permission to survey all of the hospitals (Ref. No.HB.209/450/01A/135). As no patient or provider identifying details were kept, and no patient contact was made, no patient consent was required.

Provenance and peer review Not commissioned; externally peer reviewed.

Data availability statement Data are available upon reasonable request. Extra data are available on reasonable request. For those who would like to request additional data, they can e-mail to (hsawe@muhas.ac.tz).

Open access This is an open access article distributed in accordance with the Creative Commons Attribution Non Commercial (CC BY-NC 4.0) license, which permits others to distribute, remix, adapt, build upon this work non-commercially, and license their derivative works on different terms, provided the original work is properly cited, appropriate credit is given, any changes made indicated, and the use is non-commercial. See: http://creativecommons.org/licenses/by-nc/4.0/.

\section{ORCID iDs}

Hendry R Sawe http://orcid.org/0000-0002-0395-5385

Lee A Wallis http://orcid.org/0000-0003-2711-3139

\section{REFERENCES}

1 Haagsma JA, Graetz N, Bolliger I, et al. The global burden of injury: incidence, mortality, disability-adjusted life years and time trends from the global burden of disease study 2013. Inj Prev 2016;22:3-18.

2 Krug EG, Sharma GK, Lozano R. The global burden of injuries. Am J Public Health 2000;90:523-6.

3 Reynolds TA, Stewart B, Drewett I, et al. The impact of trauma care systems in low- and middle-income countries. Annu Rev Public Health 2017;38:507-32.

4 Mock C, Joshipura M, Arreola-Risa C, et al. An estimate of the number of lives that could be saved through improvements in trauma care globally. World J Surg 2012;36:959-63.

5 Nwomeh BC, Lowell W, Kable R, et al. History and development of trauma registry: lessons from developed to developing countries. World J Emerg Surg 2006;1:32.

6 Cales RH, Bietz DS, Heilig RW. The trauma registry: a method for providing regional system audit using the microcomputer. $J$ Trauma 1985;25:181-6.

7 Chokotho LC, Mulwafu W, Nyirenda M, et al. Establishment of trauma registry at Queen Elizabeth central Hospital (QECH), Blantyre, Malawi and mapping of high risk geographic areas for trauma. World J Emerg Med 2019;10:33-41.

8 O'Reilly GM, Cameron PA, Joshipura M. Global trauma registry mapping: a scoping review. Injury 2012;43:1148-53.

9 Boniface R, Museru L, Kiloloma O, et al. Factors associated with road traffic injuries in Tanzania. Pan Afr Med J 2016;23:46.

10 Mukhopadhyay B, Boniface R, Razek T. Trauma in Tanzania: researching injury in a low-resource setting. Mcgill J Med 2009;12:27.

11 Kobusingye OC, Lett RR. Hospital-based trauma registries in Uganda. J Trauma 2000;48:498-502.

12 Chalya PL, Dass RM, Mchembe MD, et al. Citywide trauma experience in Mwanza, Tanzania: a need for urgent intervention. $J$ Trauma Manag Outcomes 2013;7:9.

13 Mfinanga JA, Sawe HR, Mwafongo V, et al. Paediatric trauma causes, patterns and early intervention at the Muhimbili national hospital emergency department in Dar ES Salaam, Tanzania. African J Emerg Med 2013;3:S7.

14 WHO. WHO standardized clinical form, 2020. Available: https://www. who.int/publications/i/item/who-standardized-clinical-form

15 Ministry of Health. Tanzania health management information system, 2017. Available: www.dhis.moh.go.tz [Accessed 27 Jun 2020].

16 Nyamtema AS. Bridging the gaps in the health management information system in the context of a changing health sector. $B M C$ Med Inform Decis Mak 2010;10:36.

17 Wilms MC, Mbembela O, Prytherch $\mathrm{H}$, et al. An in-depth, exploratory assessment of the implementation of the National health information system at a district level hospital in Tanzania. BMC Health Serv Res 2014;14:91.

18 WHO. WHO dataset for injury. Available: https://www.who.int/ publications/m/item/who-dataset-for-injury [Accessed $30 \mathrm{Jul}$ 2020].

19 Sawe HR, Reynolds TA, Weber EJ, et al. Trauma care and capture rate of variables of World health organisation data set for injury at regional hospitals in Tanzania: first steps to a national trauma registry. BMC Emerg Med 2020;20:29.

20 Sawe HR, Sirili N, Weber E, et al. Barriers and facilitators to implementing trauma registries in low- and middle-income countries: qualitative experiences from Tanzania. African J Emerg Med 2020.

21 Susman GI, Evered RD. An assessment of the scientific merits of action research. Adm Sci Q 1978;23:582.

22 Sawe HR, Sirili N, Weber E, et al. Perceptions of health providers towards the use of standardised trauma form in managing trauma patients: a qualitative study from Tanzania. Inj Epidemiol 2020;7:15.

23 Wilkinson D, McDougall R. Primary trauma care. Anaesthesia 2007;62:61-4.

24 Moore L, Clark DE. The value of trauma registries. Injury 2008;39:686-95.

25 Kehoe A, Smith JE, Edwards A, et al. The changing face of major trauma in the UK. Emerg Med J 2015;32:911-5.

26 Moran CG, Lecky F, Bouamra O, et al. Changing the system - major trauma patients and their outcomes in the NHS (England) 2008-17. EClinicalMedicine 2018;2-3:13-21. 
27 Mehmood A, Razzak JA, Kabir S, et al. Development and pilot implementation of a locally developed trauma registry: lessons learnt in a low-income country. BMC Emerg Med 2013;13:4.

28 Primary Trauma Care. Primary trauma care foundation. Available: https://www.primarytraumacare.org

29 WHO. WHO International registry for trauma and emergency care, 2020. Available: https://www.who.int/news-room/detail/01-11-2018who-international-registry-for-trauma-and-emergency-care

30 Koka PM, Sawe HR, Mbaya KR, et al. Disaster preparedness and response capacity of regional hospitals in Tanzania: a descriptive cross-sectional study. BMC Health Serv Res 2018;18:835.

31 Baker T, Lugazia E, Eriksen J, et al. Emergency and critical care services in Tanzania: a survey of ten hospitals. BMC Health Serv Res 2013;13:140.
32 Kuzma K, Lim AG, Kepha B, et al. The Tanzanian trauma patients' prehospital experience: a qualitative Interview-Based study. BMJ Open 2015;5:e006921.

33 Schultz CR, Ford HR, Cassidy LD, et al. Development of a hospitalbased trauma registry in Haiti: an approach for improving injury surveillance in developing and resource-poor settings. J Trauma 2007;63:1143-54.

34 Patel R, Bachu R, Adikey A, et al. Factors related to physician burnout and its consequences: a review. Behav Sci 2018;8:98.

35 Chalya PL, Mabula JB, Dass RM, et al. Injury characteristics and outcome of road traffic crash victims at Bugando medical centre in northwestern Tanzania. J Trauma Manag Outcomes 2012;6:1.

36 McCambridge J, Witton J, Elbourne DR. Systematic review of the Hawthorne effect: new concepts are needed to study research participation effects. J Clin Epidemiol 2014;67:267-77. 